\title{
Change of Pressing Chamber Conicalness at Briquetting Process in Briquetting Machine Pressing Chamber
}

\author{
Peter Križan ${ }^{1}$, Miloš Matúš ${ }^{1}$, Jaan Kers ${ }^{2}$, Djordje Vukelić ${ }^{3}$ \\ ${ }^{1}$ Faculty of Mechanical Engineering, Slovak Technical University in Bratislava, Institute of Production Systems, \\ Environmental Technology and Quality Management, Nám. Slobody 17, 81231 Bratislava, Slovakia \\ ${ }^{2}$ Tallinn University of Technology; Department of Polymer Materials, Chair of Woodworking, Teaduspargi 5, \\ 12618 Tallinn, Estonia \\ ${ }^{3}$ University of Novi Sad, Faculty of Technical Sciences, Trg Dositeja Obradovica 6, 21000 Novi Sad, Serbia
}

Correspondence to: peter.krizan@stuba.sk

\begin{abstract}
In this paper, we will present the impact of the conical shape of a pressing chamber, an important structural parameter. Besides the known impact of the technological parameters of pressing chambers, it is also very important to pay attention to their structural parameters. In the introduction, we present a theoretical analysis of pressing chamber conicalness. An experiment aimed at detecting this impact was performed at our institute, and it showed that increasing the conicalness of a pressing chamber improves the quality of the final briquettes. The conicalness of the pressing chamber has a significant effect on the final briquette quality and on the construction of briquetting machines. The experimental findings presented here show the importance of this parameter in the briquetting process.
\end{abstract}

Keywords: biomass; briquetting; pressing chamber shape, pressing chamber conicalness.

\section{Introduction}

The briquetting process is a very interesting biomass treatment process. It is a very complicated process, because many parameters influence the process and the quality of the final briquettes. Briquette quality is defined by EU standards, and is evaluated by mechanical and chemical-thermic indicators.

Briquette quality is evaluated mainly by density. Briquette final density is influenced by many parameters. On the basis of the experience that we have acquired and the analyses that we have made, we can divide the parameters into the following three groups [3]:

- material parameters

- technological parameters

- structural parameters.

\section{Influencing parameters in the briquetting process}

The material parameters emerge from the properties of the pressed material, i.e. material moisture, fraction size, chemical composition of the material, etc.

The technological parameters are pressing temperature, compacting pressure, compacting speed, holding time, etc. These parameters can be changed in the course of pressing according to the capabilities of the briquetting machine.

The structural parameters of the pressing chamber are also very important. For successful pressing of high-quality briquettes, all the parameters have to be in synergy. For an engineer, it is very important to know the behaviour of all parameters. We know that pressing temperature, material moisture, compacting pressure and fraction size are very important for briquetting. We can obtain briquettes of suitable quality by adjusting the optimal values of these parameters according to the material that is to be pressed. We know that we can achieve better results by changing some of the structural parameters. It is therefore is very desirable to optimize the geometry of the pressing chamber. The main structural parameters influencing the final briquette density are $[2,6]$ :

- the diameter of the pressing chamber

- the length of the pressing chamber

- the conical shape of the pressing chamber

- the friction coefficient between the chamber and the pressing tool

- the length of the cooling channel

- the effect of counter pressure in the pressing chamber (created in various ways)

At our institute we have designed an experimental pressing stand (see Figure 1) on which we are 

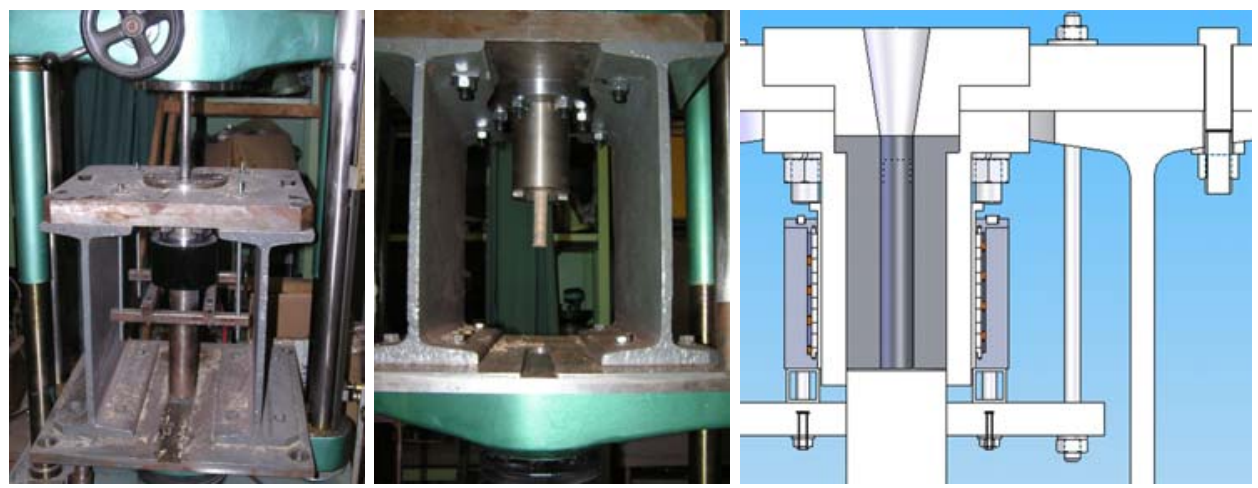

Figure 1: Experimental pressing stand with heating equipment [2]

able to perform experiments to detect the impact of each of the parameters listed above. In this paper, we will present our findings on the conical shape of the pressing chamber. Why is it so important to know the impact of changes in the conicalness of the pressing chamber? A pressing chamber with a conically-shaped wall is very often used in briquetting and pelleting machinery. However, we know of no studies that clearly show the interaction between final briquette density and changes in pressing chamber conicalness.

\section{Theoretical analysis of pressing chamber conicalness}

The geometry of the pressing chamber is very important in briquetting. However, few studies of the briquetting process have shown the influence of individual parameters of this process, taking into account the pressing conditions in the pressing chamber during briquetting. The results presented in this paper are based on our experience, and on a comparison between our experimental results and analyses, on the one hand, and the existing mathematical model of pressing, on the other.

We have attempted to find some equations or mathematical models that can be used for calculating the pressing conditions in the pressing chamber. In [1], Horrighs offers a clear description of the pressing conditions in a cylindrically-shaped pressing chamber. This theory is represented by the following mathematical model (1):

$$
p_{G}=p_{k} \cdot \mathrm{e}^{-\frac{4 \cdot \lambda \cdot \mu \cdot H}{D_{k}}} \quad(\mathrm{MPa})
$$

where $p_{G}$ is the counter pressure in the chamber, $p_{k}$ is the axial pressure of the hydraulic press, $\lambda$ is the ratio of the main strains $\sigma_{r} / \sigma_{m}$, and $\mu$ is the friction coefficient, $H$ is the length of a pressed briquette and $D_{k}$ is the diameter of the pressing chamber.
The situation regarding the pressing conditions in the conical chamber is somewhat complicated. The pressed material in the chamber is subjected to multiaxial pressing. This increases the pressing quality: it increases the briquette density and also the mechanical properties of the briquettes. However, the tool wear is also increased. We have often replaced a cylindrical pressing chamber by a conical pressing chamber and obtained briquettes of higher density. However, there is no mathematical model for a conical pressing chamber. We are therefore attempting to design a mathematical model for a conical pressing chamber.

For an analysis of the influence of changes in conical pressing chambers, we used the theory of forward extrusion [4] as a basic metal volume moulding technology. In this definition, the force and pressure distribution is very close to the theory of biomass briquetting. A simple scheme of the main parts of a conical pressing chamber is shown in Figure 2 (left and middle). This type of pressing chamber is often used in the structure of briquetting machines. The pressing chamber consist of 3 basic parts - a cylindrical part, a conical (reductive) part and a calibration part. The material is filled into the cylindrical part and then starts to be compacted by the pressing piston. The main pressing of the material takes place in the conical part. The pressure and the conical chamber cause a multi-axial pressing effect. Some holding time while the pressed briquette is under pressure is necessary in order to eliminate pressing expansion. The calibration part gives the final shape to the briquette and provides the holding time under pressure and temperature.

Figure 2 (right) provides a better description of the pressing conditions in a conical chamber, and shows all the acting forces and pressures. The maximum attained axial pressure $P_{K}$ depends on the length of the pressing chamber $L$, on the shape of the pressing chamber, on the size of the vertex angle of the conical chamber, and on the friction conditions between the pressed material and the wall of the 

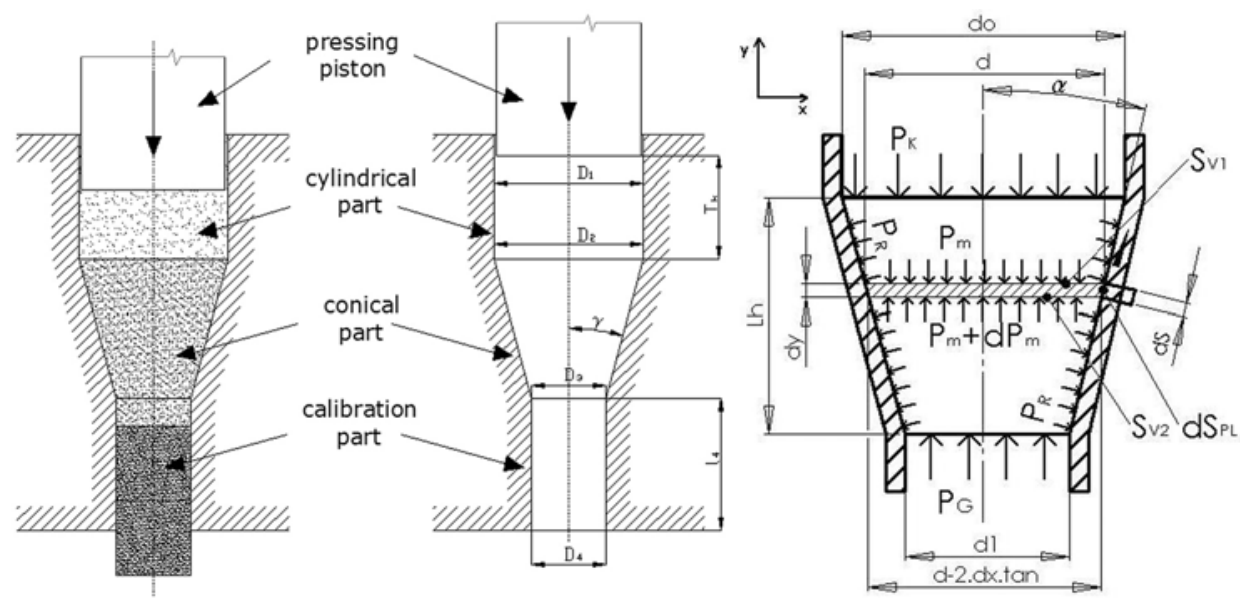

Figure 2: Main parts of a conical pressing chamber (left and middle), and the pressing conditions in a conical pressing chamber (right) $[2,4-6]\left(P_{K}\right.$ - axial pressure of press $(\mathrm{MPa}), P_{G}$ - counter pressure in chamber $(\mathrm{MPa})$, $P_{R}$ - radial pressure $(\mathrm{MPa}), P_{M}$ - axial pressure on the briquette $(\mathrm{MPa}), d_{0}$ - input diameter of the pressing chamber $(\mathrm{mm}), d_{1}$ - output diameter of the pressing chamber $(\mathrm{mm}), d$-diameter of the pressing chamber in cross-section (mm), $\mu$ - friction coefficient $(-), L$ - length of the conical part of the pressing chamber (mm))
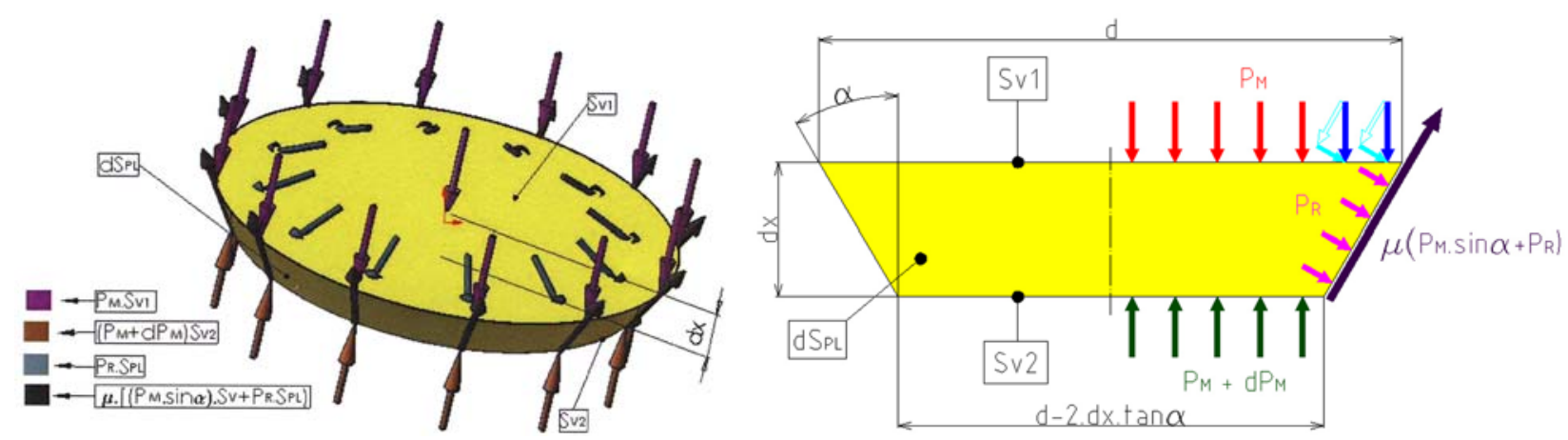

Figure 3: Pressure distributions in space (left) and plane pressure distributions (right) on a conically-shaped element

chamber. The surface friction drag is given by the radial pressure $P_{R}$, by the cross factor of pressure $P_{M}$, which affects the wall of the chamber, by the friction coefficient $\mu$, and by the length of the pressing chamber $L$. The diameter of the chamber decreases linearly according to the length of the chamber $L$.

For a description of the pressing process, we have to start with a description of the pressures acting on an element of $\mathrm{d} x$ thickness cut in a conical shape (see Figure 3 left). In the vertical direction, the axial compacting pressure $P_{M}$, acting in the opposite direction, elicited $P_{M}+\mathrm{d} P_{M}$. The friction also increases the pressure perpendicular to the wall of chamber $P_{R}$.

To make a balanced equation, we will need to know the sizes of the surfaces on which the pressures act. On the basis of the plane pressure distributions (see Figure 3, right) we were able to write the following equation (2):

$$
\begin{array}{r}
P_{M} \cdot S_{V 2}+P_{M} \cdot S_{V}-\left(P_{M}+\mathrm{d} P_{M}\right) \cdot S_{V 2}- \\
\mu \cdot\left(P_{R}+P_{M} \cdot \sin \alpha\right) \cdot \mathrm{d} S_{P L} \cdot \cos \alpha=0
\end{array}
$$

In order to implement equation (2) it will be necessary to define the border conditions and to define the final shape of a mathematical model suitable for optimization methods. This mathematical manipulation has not yet been finalized, so we are not yet able to present a mathematical model for a conical pressing chamber.

\section{A experiment to measure the impact of conicalness}

The next step was to measure the impact of conicalness. We attempted to measure the interaction between changes in pressing chamber conicalness and final briquette density. For this experiment we used an experimental pressing stand. It was necessary to prepare some new components - new chambers with different wall conics (see Figure 4).

For the experiment we prepared three new chambers with $1^{\circ}, 2^{\circ}$ and $3^{\circ}$ degree conic walls. The results were evaluated in terms of final briquette density. We compared briquettes pressed in a conical chamber with briquettes pressed in a cylindrical chamber under the same conditions. 

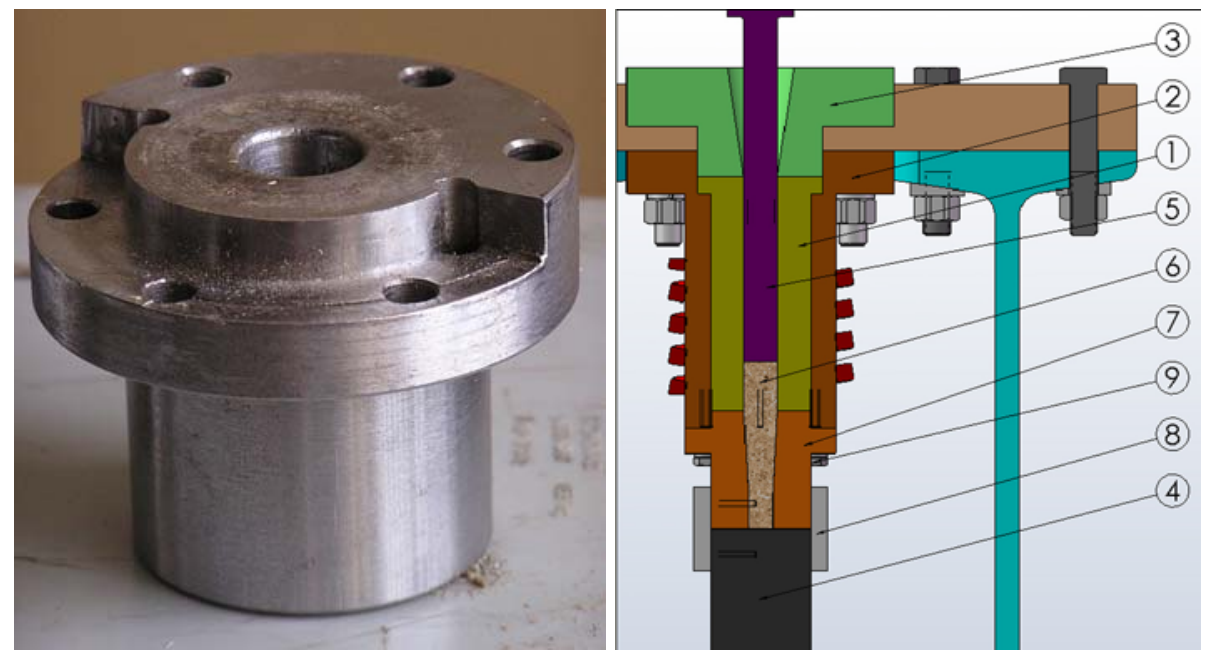

Figure 4: Example of a new chamber with a conical wall (left), and the cross-section of pressing stand (right) (1 - pressing chamber; 2 - flange; 3 - start-up chamber; 4 - counter plug; 5 - piston; 6 - pressed material; 7 - chamber with a conical wall; 8 - sleeve connector; 9 - mounting screw)

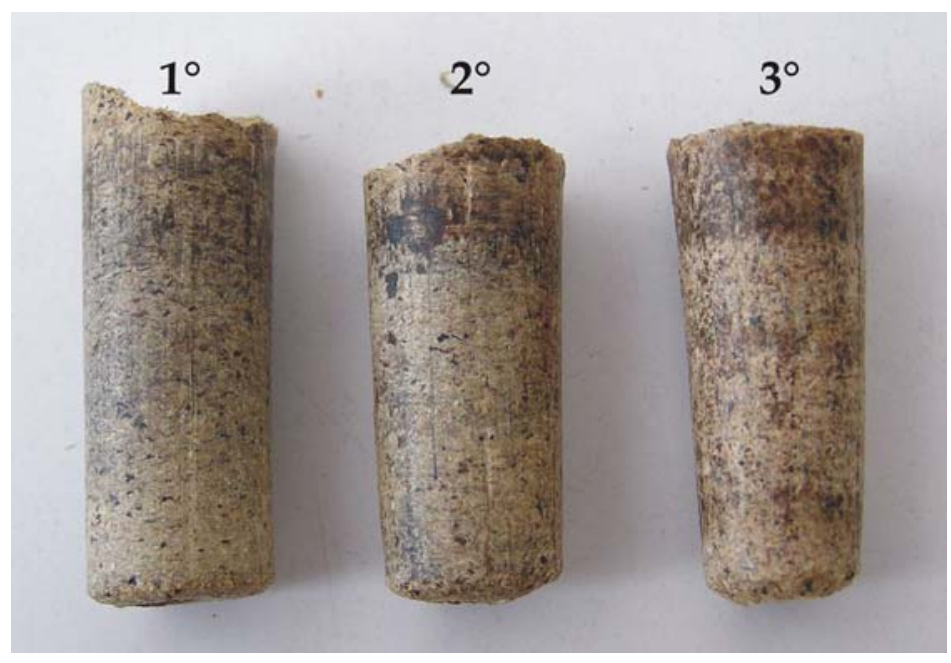

Figure 5: Negatives of internal chamber space representing different geometries

Table 1: Experiment results — density of pressed briquettes, in $\mathrm{kg} / \mathrm{dm}^{3}$

\begin{tabular}{|l|c|c|c|}
\hline & $T_{1}=20^{\circ} \mathrm{C}$ & $T_{2}=85^{\circ} \mathrm{C}$ & $T_{3}=120^{\circ} \mathrm{C}$ \\
\hline$\alpha=0^{\circ}$ & 0,852 & 1,152 & 1,207 \\
\hline$\alpha=1^{\circ}$ & - & 1,221 & 1,216 \\
\hline$\alpha=2^{\circ}$ & - & 1,236 & 1,224 \\
\hline$\alpha=3^{\circ}$ & - & - & - \\
\hline
\end{tabular}

$* \alpha$ represents the conicalness of the chamber

We chose the following conditions for this experiment: pressed pine sawdust material, material moisture $8 \%$, fraction size $1 \mathrm{~mm}$, compacting pressure $159 \mathrm{MPa}$. The pressing was done without the use of additional heating equipment, i.e. without a pressing temperature effect. The measurements were carried out in laboratory conditions, at temperature $20^{\circ} \mathrm{C}$. For each setting we pressed 7 briquettes. These were measured, and then we were able to calculate their density. Table 1 presents the results, with only the average briquette density value. The average values were compared.

For pressing without additional pressing temperature (under laboratory conditions) we did not obtain any briquettes. The first column of Table 1 $\left(20^{\circ} \mathrm{C}\right)$ therefore only shows the briquette density obtained by pressing with a cylindrically-shaped chamber. The problem was the very high friction force between the pressed material and the chamber wall. The pressing forces in the pressing chamber are distributed as a laminar flow in a cylindrical pipe (see 

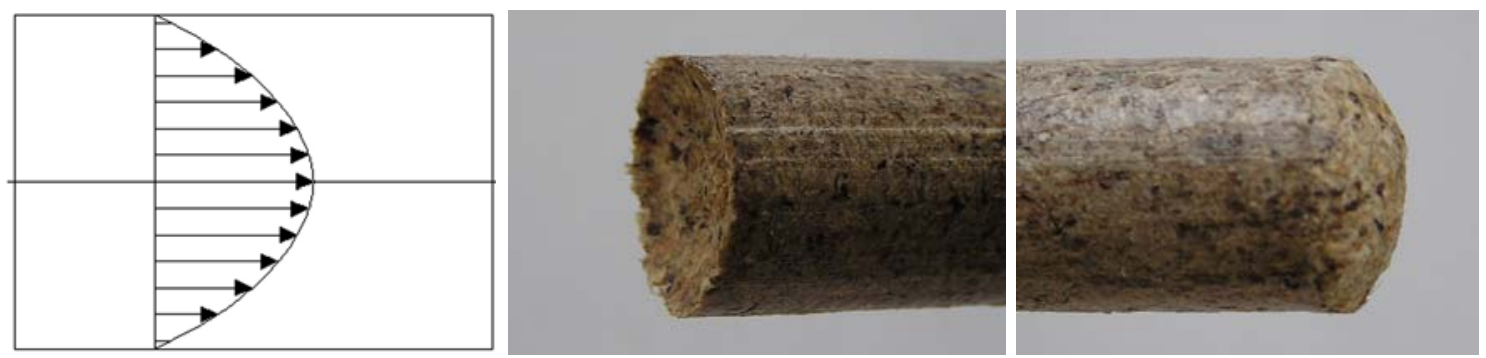

Figure 6: Pressing force distribution across the pressing chamber

Figure 6, left). The maximum axial pressing force is applied in the axial axis of the pressing chamber, see Figure 6, middle and right. The experimental pressing stand is inserted into the hydraulic press, which can exert a maximum pressing force for 10 tons. In our case, this corresponds to compacting pressure $318 \mathrm{MPa}$. We also used also the maximum pressure, but without success.

From our experience, we know that the friction force for briquetting can be reduced by lignin plastification. The friction force can be reduced by increasing the pressing temperature. For this purpose, we used heating equipment affixed to the pressing chamber. The heating equipment was controlled by a regulator that works on the basis of a signal coming in from the temperature sensor. Lignin is a material component of all types of biomass. In the briquetting process, it has the function of a gluing medium, strongly joining the particles of the material into a compact briquette.

We then decided to repeat the experiment at a different pressing temperature. The results are presented in Table 1 . With a higher pressing tempera- ture we were able to obtain briquettes. We can add that the briquette density increases as the wall angle in the chamber increases, at each temperature level. We also proved that increasing the pressing temperature has a positive impact on the friction forces between the pressed material and the chamber wall. However, we found that a chamber with a $3^{\circ}$ degree wall cannot be used in our conditions. The experiment with this chamber was not successful, because the mounting screws were destroyed during pressing. The maximum strength of the hydraulic press was also insufficient to extrude the pressed briquette from the conical chamber. During the second squeezing, the screws were destroyed.

Another interesting finding during the experiment was that we were able, during pressing, to recognize three compacting pressure values. The first value represents pressing, the second represents overcoming the friction force, and the third represents extruding the pressed briquette from the chamber. The following figures present a graphic record of these three pressures values, as recorded by the hydraulic press.
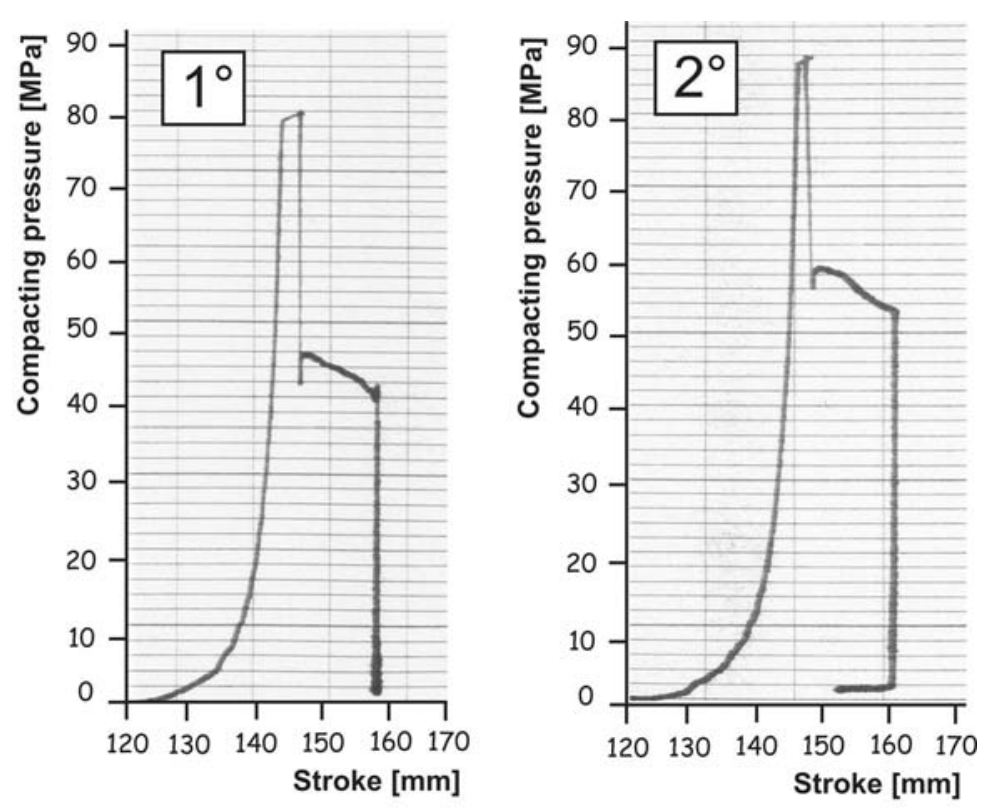

Figure 7: Graphic record of briquette pressing in conical chambers at $120{ }^{\circ} \mathrm{C}$ pressing temperature 


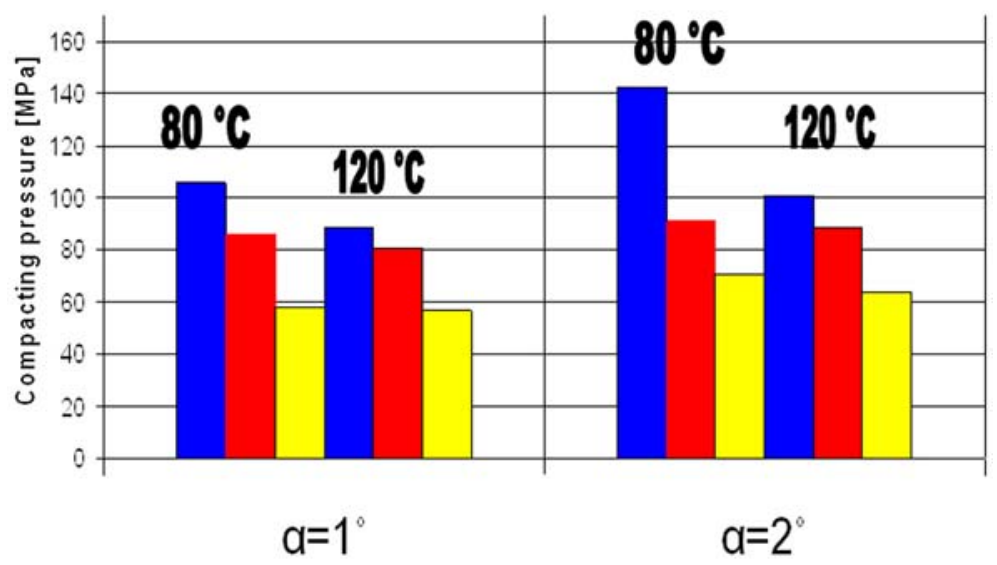

Figure 8: Comparison of recognized pressures for pressing in conical chambers (blue columns represent the pressure needed to overcome the friction force, red columns represent pressing, and yellow columns represent the pressure needed to extrude the pressed briquette from the chamber

These figures prove that during pressing with conical chamber acting higher pressures as with cylindrical chamber. This proves that higher briquette density can be obtained by pressing in a conical chamber. We can state that it is possible to increase the pressures acting in the chamber by changing the degree of conicalness of the chamber. However, it can be seen that higher friction forces act in a conical chamber with a higher degree of conicalness. The friction forces can be reduced by a higher pressing temperature. As the pressing temperature increases, the compacting pressure action decreases.

A future study should investigate the unit production costs (energy costs and production costs).

\section{Conclusion}

The main aim of this paper has been to present the results of our experiment to detect the impact of the conical shape of pressing chambers. We also wanted to show the importance of this type of parameter for the briquetting process. In the near future, we aim to design a mathematical model for a conically-shaped pressing chamber. Of course, more experiments will need to be made. With this model, we will be able to calculate the optimal length of a conical pressing chamber in accordance with the standards for the final density of briquettes.

\section{Acknowledgement}

This paper is an outcome of the project "Development of progressive biomass compacting technology and the production of prototype and high-productive tools" (ITMS Project code: 26240220017), on the basis of the Operational Programme Research and
Development support funding by the European Regional Development Fund.

\section{References}

[1] Horrighs, W.: Determining the dimensions of extrusion presses with a parallel-wall die channel for the compaction and conveying of bulk solids, Aufbereitungs - Technik: Magazine. Duisburg : Germany, 1985, No. 12.

[2] Križan, P.: Process of wood waste pressing and conception of press construction, Dissertation work, FME SUT in Bratislava, Slovakia, July 2009, p. 150, (in Slovak).

[3] Šooš, L', Križan, P.: Analysis of the interaction of forces in the pressing chamber of a briquetting machine, Proceedings of the 11th International Conference TOP 2005, Častá - Papiernička, Slovakia, 29. 6.-1. 7. 2005, FME STU in Bratislava, p. 299-306, (in Slovak). ISBN 80-227-2249-9.

[4] Storožev, M. V., Popov, J. A.: Theory of metal shaping. Bratislava, Slovakia : Alfa, Praha : SNTL, 1978, 63-560-78, p. 488, (in Slovak).

[5] Križan, P., Šooš, L'., Vukelić, Dj.: Action of counter pressure on compacted briquettes in a pressing chamber, Proceedings of the $10^{\text {th }}$ International Scientific Conference, 9.-10. 10. 2009, Novi Sad, Serbia : Faculty of Technical Sciences, 2009, p. 136-139. ISBN 978-86-7892-223-7.

[6] Križan, P., Vukelić, Dj.: Shape of the pressing chamber for wood biomass compacting, International Journal for Quality Research, Vol. 2, No. 3 (2008), ART GRAFIKA d.o.o. Podgorica, Montenegro, p. 205-209. ISSN 1800-6450. 